\title{
INOVANDO NA PÓS-GRADUAÇÃO: A EXPERIÊNCIA DO MBA DA EAESP/FGV
}

\author{
Fátima Bayma de Oliveira \\ E-mail fbayma@fgvrj.br \\ Professora da Escola de Administraçāo Pública \\ da FGV e da Universidade Santa Úrsula/RJ.
}

RESUMO: O artigo aborda a problemática do redesenho dos programas de pós-graduaçāo e analisa as várias questōes que vêm sendo discutidas neste campo: o desenvolvimento de cursos alternativos de pós-graduação, a redução do número de créditos do mestrado e o enxugamento dos programas deste nivel, com vistas à diminuiçāo do tempo médio de duraçāo dos cursos. Sob esta perspectiva, é apresentada a experiência da EAESP/FGV (Escola de Administraçāo de Empresas de São Paulo, da Fundação Getūlio Vargas) no desenvolvimento do MBA (Master in Business Administration), experiência pioneira que vem ao encontro da necessidade de inovaçōes na pós-graduaçāo em Administraçāo.

ABSTRACT: This paper deals with the redesign of graduate courses and analyses several aspects which are being discussed in this area: the development of others graduate courses, the reduction of credit numbers and the shortening of course terms, aiming the decrease of the average duration of these programs. A pionner experience in graduate Business Management programs, the EAESP/FGV case, is discussed along this perspective.

PALAVRAS-CHAVE: mestrado profissionalizante, pós-graduação lato sensu, MBA.

KEYWORDS: professional master degree, graduate courses lato sensu, Master in Business Administration. 
Ultimamente tem-se falado muito nas expressões "flexibilizar estruturas organizacionais", "flexibilizar relaçōes econômicas". Flexibilidade ou flexibilizaçāo é a palavra da moda. Até mesmo o presidente Fernando Henrique Cardoso a tem incorporado em seus discursos.

$\mathrm{Na}$ verdade, o fenômeno da flexibilização não é um modismo, mas resulta, sim, de uma necessidade gerada do acelerado ritmo com que as mudanças vêm ocorrendo, principalmente no campo de ciência e tecnologia.

No âmbito dessas transformaçōes é fundamental o papel da pós-graduação. Os cursos deste nível têm sido cada vez mais valorizados pelas empresas preocupadas com a capacitação de seus recursos humanos, conscientes da necessidade de contar, em seus quadros, com pessoas qualificadas, capazes de apresentar respostas aos desafios que surgem. Por outro lado, a proliferação desses programas está associada à valorização, pela sociedade, da figura do profissional especialista mas também generalista, que, na busca incessante do saber, deve passar por um constante processo de aprendizagem.

No bojo dessas mudanças, é importante que se discuta também a flexibilidade do sistema de pós-graduação.

Um curso de pós-graduação tem três objetivos:

- formar professores para o magistério superior, com o propósito de atender a expansão quantitativa do ensino de terceiro grau e contribuir para a elaboração de sua qualidade;

- formar pesquisadores para o trabalho científico;

- preparar profissionais de nível elevado, em função da demanda do mercado de trabalho nas instituições públicas e privadas. 1 .

Esses objetivos dizem respeito ao sistema geral de pós-graduação, incluindo, portanto, tanto os cursos de caráter stricto sensu como os de lato sensu.

Há, no entanto, um consenso de que os cursos de doutorado estão vinculados a pesquisas, estando voltados para o alar- gamento do conhecimento e para a criação de novos saberes. No caso dos cursos de mestrado, os três objetivos podem ser a eles atribuídos, podendo prevalecer um ou mais desses propósitos dependendo da ênfase dada no programa.

Esses múltiplos objetivos evidenciam que há flexibilidade na estruturação de um curso de pós-graduação, o que permite atender a demandas e interesses de clien-

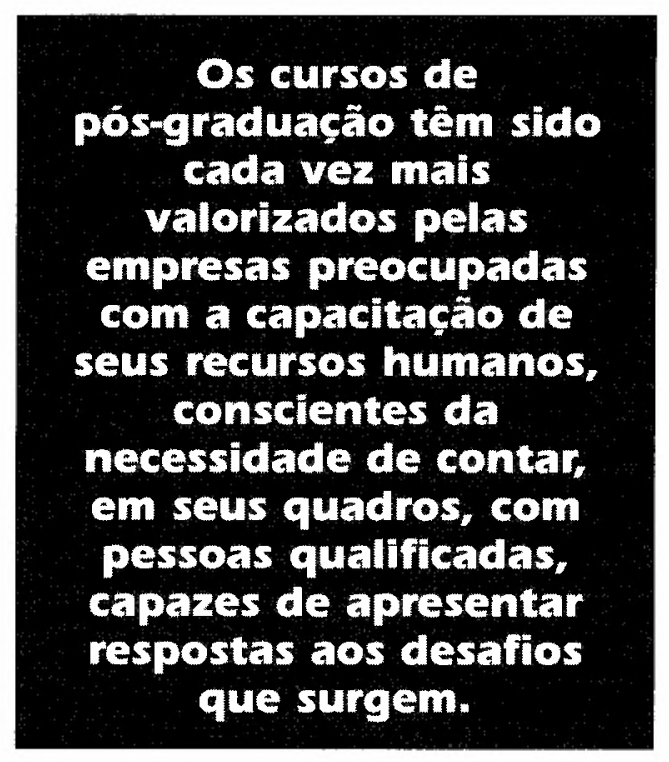

telas diferenciadas. Na prática, os cursos de mestrado não têm muito claro que produto desejam fornecer, agregando num mesmo grupo clientelas diferenciadas, ou seja, pessoas com a intenção de obter formação mais teórica e outras, de buscar conteúdos mais próximos da realidade empresarial.

Os cursos de mestrado têm sido criticados por estarem voltados para a formação de professores e pesquisadores. $\mathrm{Na}$ área de Administração, o contingente de participantes enviados por empresas ou com o objetivo de ingressar no setor empresarial costuma ser maior do que aquele de pessoas que pretendem seguir carreira acadêmica.

Um outro dado é que os programas de mestrado no país têm sido considerados improdutivos, em razão do extenso período de vinculação dos alunos, dos quais poucos alcançam a titulação de mestre. Entre os fatores que contribuem para esta
1. BAYMA, Fátima. Pós-graduaçảo: educação e mercado de trabalho. Sāo Paulo: Papirus, 1995. 
situação, destacam-se as exigências excessivas para o desenvolvimento de monografias, equiparando-se, em muitos casos, ao rigor das teses de doutorado. Para aqueles que atuam ou pretendem atuar no setor empresarial esse tipo de dissertação não desperta o interesse.

Em face dessa realidade, tem sido amplamente discutida a questão do redesenho da pós-graduação: uma questão ampla, que engloba desde o desenvolvimento de programas alternativos, como, por exemplo, de cursos mais voltados para as necessidades de empresas, até a redução do número de créditos do mestrado. O redesenho também passa pela possibilidade de aproveitamento de créditos entre os cursos que compóem o sistema de pós-graduação. Diante da complexidade dessas questões, as instituições de ensino superior (IES) vêm reagindo de forma diferenciada a essa proposta de redesenho não só das diversas áreas de conhecimento, mas também de áreas específicas.

$\mathrm{Na}$ verdade, vários aspectos dessa proposta não são idéias ou sugestōes novas. Muitas remontam ao início da década de 80, quando, no II Plano Nacional de PósGraduação ${ }^{2}$, foi dada ênfase ao desenvolvimento de programas alternativos neste nível.

As IES de qualidade, com experiências consolidadas, sāo as mais indicadas para inovar, mas o conservadorismo e o receio de aviltamento da pós-graduação em muitos casos desestimula a mudança. Por outro lado, o desenvolvimento de programas alternativos de qualidade requer não só

2. BRASIL, Governo Federal. Decreto 87.814. Diário Oficial, 16 de novembro de 1982. (II Plano Nacional de Pós-Graduação.)

3. A EAESP/FGV foi a primeira instituição a promover cursos de pós-graduação em Administração: implementou em agosto de 1958 o CPG - Curso de PósGraduaçāo. As IES de qualidade, com experiências consolidadas, stäo as mais indicadas para inovar, mas o conservadorismo e 0 receio de aviltamento da pós-graduação em muitos casos desestimula a mudançta. repensar a criação de disciplinas para o atendimento de novas clientelas, como também o envio de professores ao exterior, para realizar cursos e também visitar vários centros de excelência. Além disso, não basta um corpo de professores com doutorado; é necessário ainda que estes tenham experiência em empresas, de forma a conduzir o curso integrando a contento as dimensões teóricas e práticas.

Apesar de não haver consenso sobre a questão do redesenho da pós-graduação e de esta idéia não estar suficientemente amadurecida na comunidade, algumas IES vêm introduzindo mudanças nos cursos deste nível.

Abordaremos, a seguir, a experiência da EAESP / FGV (Escola de Administraçāo de Empresas da Fundação Getúlio Vargas), que lançou o Master in Business Administration (MBA), de caráter stricto sensu.

\section{A EXPERIÊNCIA INOVADORA DA EAESP/FGV}

A origem da idéia do MBA está relacionada à percepçāo, pelo corpo de professores da EAESP/FGV, da necessidade de se segmentarem os públicos. Tradicionalmente, o Curso de Mestrado em Administraçāo de Empresas (CMAE) reunia uma população com objetivos diferentes, sendo que somente parte dela tinha interesse acadêmico. Este fato não permitia à Escola satisfazer adequadamente os participantes, já que era difícil conciliar num mesmo discurso o enfoque predominantemente acadêmico e o teórico, técnico-profissional, desejado por aqueles que pretendiam agir no mercado empresarial.

A EAESP percebeu que, entre esses alu- 
todo o cuidado para garantir um novo produto com qualidade. Com isto, buscava evitar que o MBA - um curso de mestrado, e não de especialização - passasse a ser visto como um curso para obtençāo de um título mais fácil.

Ao contrastarmos o MBA com o CMAE, verificamos que os seus programas são substantivamente diferentes, com públicos significativamente diferenciados. O recrutamento de candidatos para o MBA é diferente daquele para o CMAE. Isso permite diferenciar populaçōes com expectativas diversas, possibilitando direcionar para o CMAE aquelas que aspiram seguir a carreira acadêmica.

$\mathrm{O}$ processo de seleção ao MBA inclui prova de proficiência em inglês - Test of English as a Foreign Language (TOEFL), o Graduate Management Admission Test (GMAT) —, cartas de recomendação, entrevistas com os candidatos, prova de redação, em português, sobre temas gerais, além de currículo, histórico escolar e diploma do curso de graduação ${ }^{4}$.

Com a exigência do TOEFL e do GMAT, a EAESP procura não só manter o seu reconhecimento acadêmico no meio nacional, mas sobretudo seguir as tendências das renomadas escolas de negócios internacionais, favorecendo aos seus alunos o estabelecimento de intercâmbio com essas escolas.

São oferecidas até 50 vagas para o MBA, sendo o número de inscritos superior a 120. Os cursos do MBA têm sido realizados em tempo parcial, com duraçāo de dois anos. A fim de que os alunos possam conciliar o curso com suas atividades profissionais, as aulas são agendadas de forma especial: sete horas distribuídas em duas noites da semana, e mais sete horas e meia concentradas nas sextas-feiras (a cada três semanas, as aulas de sexta-feira são transferidas para o sábado).

O perfil da turma caracteriza-se por apresentar faixa etária entre 26 e 35 anos, com suficiente experiência profissional e interesses voltados para atividades no nível executivo ou de consultoria.

O programa dá especial ênfase ao desenvolvimento de habilidades gerenciais; a sua estrutura consiste de 28 disciplinas, das quais 22 sāo obrigatórias e seis, ele-

\begin{tabular}{|c|c|c|}
\hline \multicolumn{3}{|c|}{ Estrutura do MBA } \\
\hline$\because$ & $\begin{array}{l}\text { Contabilidade Financeira } \\
\text { Contabilidade Gerencial }\end{array}$ & $\begin{array}{l}\text { Tecnologia da Informação } \\
\text { Tecnologia da Automação }\end{array}$ \\
\hline . & $\begin{array}{l}\text { Modelagem Quantitativa } \\
\text { Análise Estatística }\end{array}$ & $\begin{array}{l}\text { Finanças Corporativas } \\
\text { Análise de Investimentos }\end{array}$ \\
\hline & $\begin{array}{l}\text { Microeconomia } \\
\text { Economia de Empresas }\end{array}$ & $\begin{array}{l}\text { Internacionalização Política } \\
\text { Internacionalização Cultural }\end{array}$ \\
\hline 8 & $\begin{array}{l}\text { Comportamento Humano } \\
\text { Comportamento Organizacional }\end{array}$ & $\begin{array}{l}\text { Política de Negócios } \\
\text { Estratégia e Ética de Negócios }\end{array}$ \\
\hline$\because$ & $\begin{array}{l}\text { Gerência de Marketing } \\
\text { Estratégia de Marketing }\end{array}$ & $\begin{array}{l}\text { Negociações Empresariais } \\
\text { Negociaçóes Internacionais }\end{array}$ \\
\hline$\because$ & $\begin{array}{l}\text { Gestão de Operações } \\
\text { Gestão de Qualidade Total }\end{array}$ & \\
\hline & $\because$ Conjuntos & Temblicos: \\
\hline & $\begin{array}{l}\text { Estratégia e instrumentos } \\
\text { financeiros }\end{array}$ & Logística \\
\hline mo & $\begin{array}{l}\text { Gestāo de RH: análise de estratégias } \\
\text { e modelos }\end{array}$ & Gestão de risco econômico \\
\hline 8 & Comunicação empresarial & Avaliaçāo de empresas \\
\hline 6\% & Administração de vendas & Macroeconomia \\
\hline 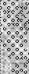 & $\begin{array}{l}\text { Psicodinâmica motivacional e } \\
\text { liderança }\end{array}$ & $\begin{array}{l}\text { Comércio internacional e } \\
\text { competitividade }\end{array}$ \\
\hline & Finanças internacionais & Diagnóstico organizacional \\
\hline & $\begin{array}{l}\text { O indivíduo na organizaçāo: } \\
\text { intrapreneuring }\end{array}$ & \\
\hline
\end{tabular}

tivas, além da dissertação de mestrado. Essas disciplinas baseiam-se nos conjuntos temáticos apresentados no quadro 1 .

Há praticamente um professor para cada disciplina, o que significa não estimular a figura do professor polivalente, que ministra várias disciplinas em um mesmo curso. Com isto, evitam-se abordagens superficiais, pouco profissionais, garantindo-se a riqueza de enfoques que contribui para a excelência do curso.

O corpo docente do MBA - formado por professores-doutores - é praticamente o mesmo daquele do mestrado tradicional, mas os professores têm o compromisso de oferecer programas diferenciados nos dois cursos de mestrado.

A carga horária dos dois tipos de mestrado é bem próxima, mas, no MBA, o tempo de curso, compactado, obriga a um ritmo mais intenso.
4. EAESP/FGV. Normas operacionais do MBA/GV. São Paulo, 1994. 
No que se refere aos critérios para a avaliação de alunos, em cada disciplina é atribuído um conceito: A, B, C ou D. O professor utiliza um sistema de distribuição de conceitos, de forma que o de nível A seja atribuído à faixa de $10-30 \%$ dos alunos com os melhores desempenhos. $\mathrm{O}$ conceito $C$, aos $10-20 \%$ com os piores desempenhos, e o $\mathrm{B}$, aos demais alunos, com desempenho mediano. Podem ser desligados do curso os alunos que acumulam em seu currículo dois conceitos $D$, sete $C$ ou dois conceitos $B$ e dois $C$, no mesmo período eletivo ${ }^{5}$.

A avaliação por curva forçada não se aplica ao mestrado tradicional. No caso do MBA, o coordenador do curso considera que esse critério, adotado em várias expe-

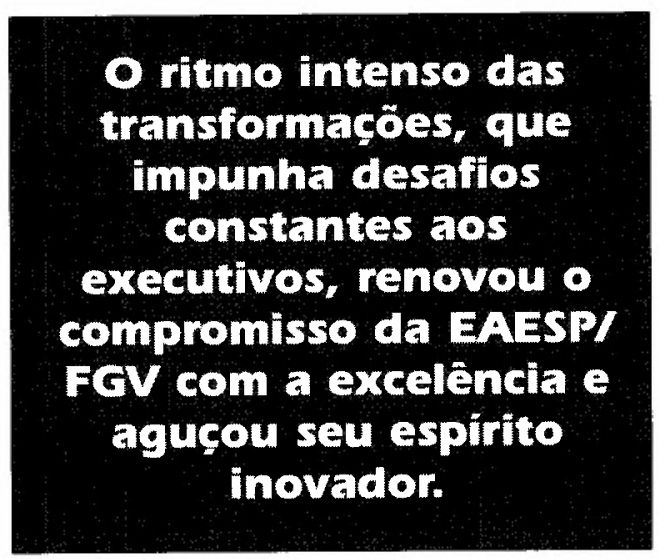

riências - bem-sucedidas - do MBA, "puxa" a média para cima. Acrescenta ainda que no meio empresarial um indivíduo não precisa ser o melhor do mundo, mas, sim, estar à frente de seus concorrentes. " $O$ mundo empresarial é assim, e estamos treinando gente para viver neste mundo." 6

É interessante observar que, como o número de disciplinas obrigatórias é elevado, resgata-se a idéia de turma. Essa forma de conduzir o curso, baseada em experiência internacional, torna o programa mais concentrado e, ao mesmo tempo, permite aos alunos maior engajamento à idéia de turma. Contribui para isso o fato de que não existe a possibilidade de trancar dis-

\section{Idem, ibidem.}

6. MANFREDINI, Antonio Carlos Abril de 1995. (Entrevista verbal)

7. SPINK, Peter. Abril de 1995. (Entrevista verbal) parte a vida empresarial - a organização da sua atividade acadêmica, e oferece um custo de oportunidade mais elevado se comparado ao dos alunos dos mestrados tradicionais. Segundo ele, é importante a criação de regras que colaborem com os objetivos da comunidade e com o perfil dos alunos. A regra de turma cria um ritmo de marcha que permite ao aluno médio cumprir os prazos estabelecidos. A possibilidade de escolha pode dar margem à dispersão; a existência de graus de liberdade para administrar não necessariamente corresponde a resultados melhores.

De acordo com a concepção de criar mecanismos que beneficiem e motivem o aluno, a EAESP incentiva os participantes a cursar algumas disciplinas em universidades no exterior, ligados ao Program in International Management (PIM). A condição para o intercâmbio no exterior é a apresentação e aprovação da dissertação, uma forma de assegurar que o aluno efetivamente finalize o curso: no seu retorno do exterior provavelmente ser-lhe-á mais difícil dar continuidade à dissertação. Com isso, grande parte dos alunos acelera o trabalho de dissertação ao longo do curso e, conseqüentemente, faz com que seja elevado o percentual de pessoas que concluem a dissertação.

Para o professor Peter Spink, a EAESP/ FGV preferiu "inovar com conservadorismo", ou seja, optou por ser conservadora em relação à mudança, visando a preservar a qualidade $^{7}$.

A EAESP resolveu manter a dissertação e preocupou-se em exigir dos participantes resultados substancialmente diferentes dos apresentados nos mestrados tradicionais.

Quanto aos parâmetros para o desenvolvimento da dissertação, o curso foi formulando gradativamente um quadro a respeito. Por exemplo, existiam algumas convicções no sentido de não se exigir erudição na revisão da bibliografia. Hoje sabese que o importante é uma dissertação que demonstre que o MBA foi útil, um dado possível de se medir por meio da transformação de um conceito teórico em uma ferramenta e na sua operacionalização. Então, a dissertação pode focalizar um estudo de viabilidade, análises de casos, crí- 
ticas de estratégias de investimento, ou seja, a teoria aplicada a um caso prático. Com isto, o MBA é colocado no contexto do mestrado profissional.

A experiência com a primeira turma permite relatar acontecimentos interessantes que podem servir como alternativa para o desenvolvimento do trabalho final. É o caso de uma disciplina cujo objetivo é estudar e propor a viabilidade de um negócio. Foi criada uma empresa, como resultado dessa disciplina, e um grupo de alunos está gerenciando o empreendimento. Essa experiência foi tão rica que irá competir com projetos semelhantes desenvolvidos pelos MBA das melhores escolas de negócios no exterior.

Um outro aspecto que vale destacar é que o MBA não inclui a disciplina Metodologia de Pesquisa na sua grade curricular. $O$ trabalho de preparação para a dissertação foi desenvolvido informalmente, fora da sala de aula, por um tutor. $O$ trabalho da tutoria consistiu em mostrar como apresentar dado problema dentro de um encadeamento lógico. Além do tutor, cada aluno, ao longo do curso, escolhe o seu orientador.

A EAESP lançará o MBA em tempo integral em 1996. O curso está previsto para durar um ano e meio. Indagados se a EAESP cogita retirar a dissertação do MBA em tempo parcial ou em tempo integral a ser lançado, em vista da experiência internacional e da seriedade com a qual vem desenvolvendo o programa, a resposta obtida foi cautelosa: "é cedo para afirmar que vamos retirar a dissertação. A experiência mostra que se usarmos a dissertação de forma inteligente, ela pode ser um belo instrumento" 8 .

Em suma, à luz das discussões travadas nos órgãos que compõem o sistema de pós-graduação e de algumas experiências desenvolvidas pelas IES, é imperativo vislumbrar formas alternativas de trabalho, de modo a evitar que a elaboração da dissertação se torne um processo penoso, sem criatividade. À guisa de exemplo, alguns programas de mestrado no exterior aceitam, mesmo os de conteúdo mais acadêmico, que a tese seja um artigo competente e passível de ser publicado numa boa revista especializada.

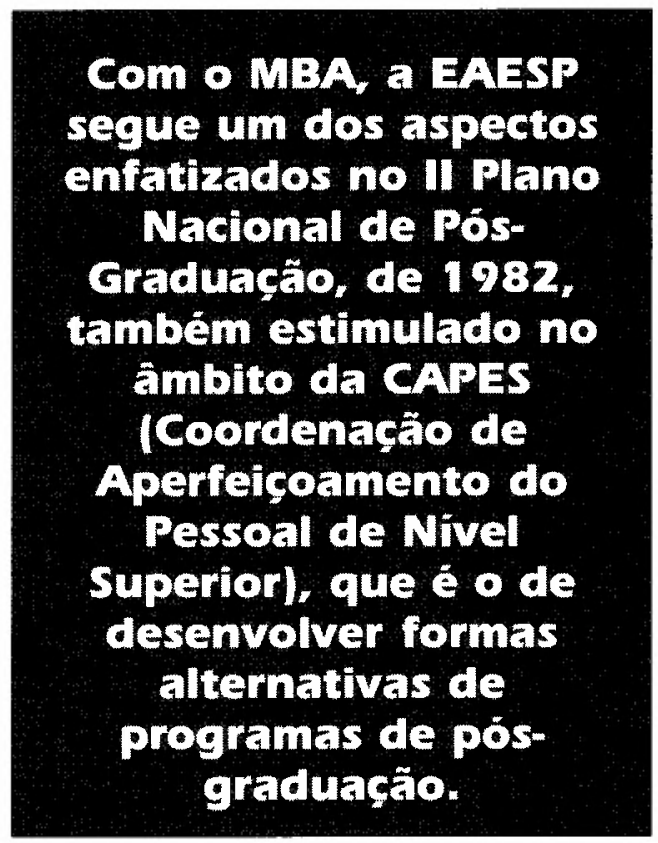

Na discussão do redesenho da pós-graduação, é focalizado também o aproveitamento de créditos dos diversos programas de pós-graduação. No caso da EAESP, não se aproveitam créditos dos cursos de pósgraduação lato sensu nos de mestrado. Há condições muito limitadas de aproveitamento, no MBA, de créditos do mestrado tradicional. $O$ conceito de que os programas de cada um desses cursos são bem diferenciados quanto aos objetivos, ao público e à metodologia, havendo estruturações específicas, dificulta o aproveitamento de créditos de um programa em outro.

Com o MBA, a EAESP segue um dos aspectos enfatizados no II Plano Nacional de Pós-Graduação, de 1982, também estimulado no âmbito da CAPES (Coordenação de Aperfeiçoamento do Pessoal de Nível Superior), que é o de desenvolver formas alternativas de programas de pósgraduação.

\section{CONSIDERAÇÕES FINAIS}

É forte a tendência de se imprimir maior flexibilidade à pós-graduação. Têm sido incentivadas propostas de elaboração de dissertações sob uma perspectiva mais variada e modesta, de forma a atender a necessidades e interesses de clientelas homogêneas; de desenvolvimento de progra-
8. MANFREDINI, Antonio Carlos. Op. cit. 
As empresas e o público

em geral devem estar

atentos para não

confundir" gato por

lebre", isto é, devem

procurar estar

informados das

especificidades dos

vários cursos de pós-

graduação. Por

exemplo, poucos sabem

diferenciar os cursos de

mestrado daqueles lato

sensu, também

conhecidos como de

especialização.

mas diferenciados de pós-graduação, levando em conta a segmentação do mercado, isto é, clientela com anseios e perfil próprios; de aproveitamento de créditos dentre os programas de pós-graduação, $\mathrm{e}$ de enxugamento dos programas de mestrado, visando a reduzir o tempo médio desses outros.

É fundamental considerar as especificidades das instituições de ensino superior e da comunidade na qual atuam. No caso das universidades federais e estaduais, tudo indica que a ênfase do redesenho estará centrada no investimento em programas de pós-graduação lato sensu. O mestrado profissional, inserido na categoria stricto sensu, dificilmente será cobrado nessas instituiçōes, em face dos dispositivos legais existentes.

Outras IES cogitam aproveitar, nos cursos de mestrado, um percentual de créditos de cursos lato sensu. No que se refere aos planos de enxugamento dos cursos, uma das idéias discutidas é que não haja mais a obrigatoriedade da dissertação. Outras alternativas para enxugar o mestrado seriam a redução do número de disciplinas e o desenvolvimento de normas mais eficientes na condução da dissertação, através de mecanismos que induzam os alunos a apresentá-la efetivamente. A questão de fundo é quanto enxugar sem prejuízo da qualidade, para que os cursos de mestrado não se tornem medíocres.

Concluindo, é grande o desafio a ser enfrentado pelas instituições de ensino superior que compõem o sistema de pósgraduação. Por um lado, sabe-se da necessidade de inovar, de buscar programas alternativos, mas, por outro, há o receio das conseqüências desse processo de flexibilização, face a alguns abusos cometidos, aviltantes. As empresas e o público em geral devem estar atentos para não confundir "gato por lebre", isto é, devem procurar estar informados das especificidades dos vários cursos de pós-graduação. Por exemplo, poucos sabem diferenciar os cursos de mestrado daqueles lato sensu, também conhecidos como de especialização. Os cursos de mestrado credenciados junto ao MEC (Ministério da Educação e Cultura) cobrem uma vasta área do conhecimento, são regulamentados e conferem diplomas reconhecidos em todo o território nacional. Os cursos de pós-graduação lato sensu conferem certificado e gozam de menor prestígio na carreira acadêmica. Observa-se, no entanto, que muitas instituições de ensino superior vêm lançando cursos, utilizando como chamariz as denominaçōes dos mestrados americanos.

Por fim, cabe às empresas e ao público em geral se apoiarem em instituições que contam com um corpo de professores qualificados e infra-estrutura adequada, $\mathrm{e}$ ao aluno cabe reivindicar cursos de qualidade.

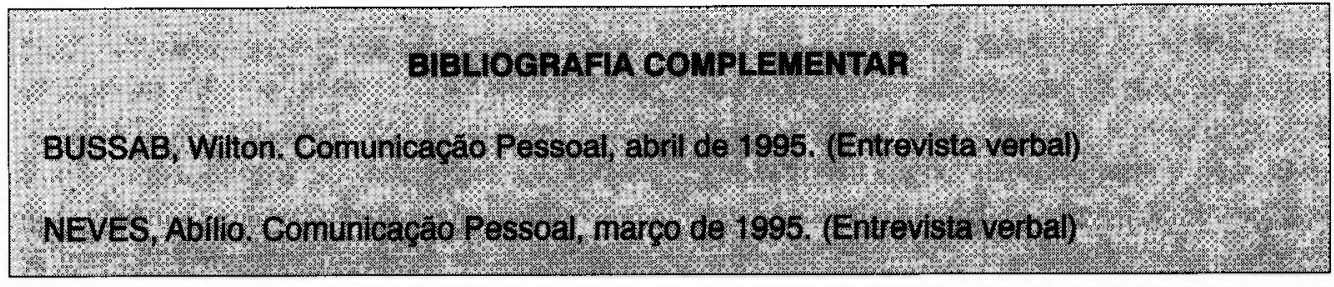

